\title{
Postinflammatory Papule: A Tentative New Designation for Acne Vulgaris
}

Toshitatsu Nogita $\cdot$ Yuko Nomura $\cdot$ Ichiro Kurokawa

Received: August 10, 2021 / Published online: October 16, 2021

(C) The Author(s) 2021

Keywords: Acne; Postinflammatory papule; New designation

\section{Key Summary Points}

A tentative new designation of "postinflammatory papule (PIP)" for acne vulgaris is proposed.

PIP is defined as brown and dark-brown papules that form from red papules and pustules, resulting in postinflammatory hyperpigmentation (PIH) and scarring.

We define PIP as transitional eruption between red papules, pustules, and postinflammatory hyperpigmentation (PIH).

To the best of our knowledge, the concept of PIP has not been described.

T. Nogita

Shinjuku Minamiguchi Dermatological Clinic,

Shinjuku, Tokyo, Japan

\section{Y. Nomura}

Nomura Dermatology Clinic, Yokohama,

Kanagawa, Japan

I. Kurokawa $(\bowtie)$

Department of Dermatology, Meiwa Hospital, 4-31,

Agenaruo-cho, Nishinomiya, Hyogo 663-8186,

Japan

e-mail: kurokawa.i@meiwa-hospital.com
We recommend topical benzoyl peroxide (BPO)/adapalene as treatment for PIP to prevent formation of atrophic scars.

Further investigation of histopathological findings in PIP is necessary to confirm whether inflammation still exists.

\section{COMMENTARY}

Acne vulgaris begins as minute pathological microcomedones. Microcomedones usually develop into either open comedones (blackheads) or closed comedones (whiteheads), both of which are visible to the naked eye and eventually develop into inflamed lesions such as red papules and pustules [1, 2]. After the inflammation subsides, inflammatory lesions turn into postinflammatory erythema (PIE) and postinflammatory hyperpigmentation (PIH), on which atrophic and hypertrophic scars may form. In addition, when the follicular walls in the comedo are dilated, cysts or nodules are formed. Furthermore, hypertrophic scars and keloids occasionally occur in acne conglobata $[1,2]$.

Postinflammatory papule (PIP) is proposed herein as a tentative new designation for acne vulgaris. PIP is defined as brown and darkbrown papules that form from red papules and 
pustules, resulting in postinflammatory hyperpigmentation (PIH) and scarring. We define PIP as transitional eruption between red papules, pustules, and postinflammatory hyperpigmentation (PIH). When inflammation (manifesting as red papules or pustules) subsides, brown and dark-brown papules remain as PIP. PIP is not a macule, such as a PIH, but a papule.

In PIP, histopathology is necessary to confirm inflammation, noninflammatory infiltration, and scar tissue. To the best of our knowledge, the concept of PIP has not yet been described. However, PIP is usually encountered in acne lesions. We observed that PIP develop after formation and resolution of inflammatory red papules and pustules, with or without medication, and this lesion can develop into three types of eruptions: PIH, hypertrophic scars, and atrophic scars. Therefore, it is important that PIP is not treated with antimicrobial therapy. Instead, we recommend topical benzoyl peroxide (BPO)/adapalene as treatment for PIP to prevent formation of atrophic scars. Topical BPO/adapalene is used to reduce the risk of acne scars [3]. Treatment of acne cannot be achieved by antimicrobial therapy alone. Topical BPO/adapalene has antiinflammatory and skin-lightening effects . In addition, PIP has been successfully treated with a Smoothbeam laser (1450-nm diode laser with cryogen spray cooling) [4].

Tan et al. described postinflammatory lesions with erythema and postinflammatory lesions with hyperpigmentation that included PIE, PIP, and PIH, and reported a standard terminology that incorrectly and inadequately described acne [5]. Moreover, a representative case of PIP was demonstrated. The color of postinflammatory papules (PIP) on the patient's mandibular area varies from brown to dark brown (Fig. 1). We hereby define PIP as a transitional eruption from red papules or pustules to $\mathrm{PIH}$. Thus, we propose a new designation as "postinflammatory papule" for acne vulgaris. Nevertheless, further case reports are necessary to establish the concept of "postinflammatory papule." In addition, histopathological studies are necessary to confirm the presence of inflammation, noninflammatory infiltration, and scar tissue in PIP.

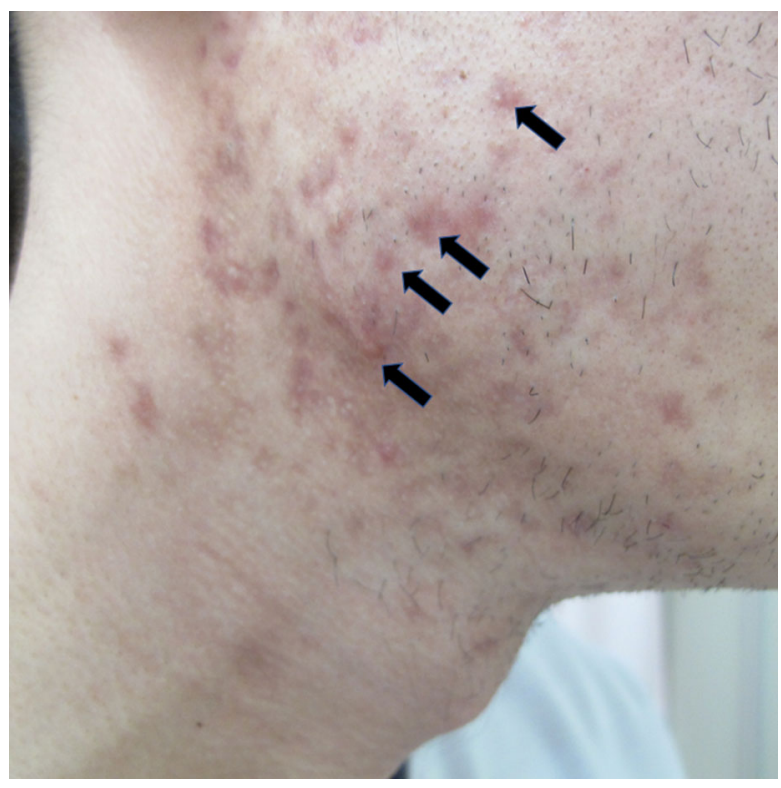

Fig. 1 The color of postinflammatory papules (PIP) (arrow) on the patient's mandibular area varies from brown to dark brown

\section{ACKNOWLEDGEMENTS}

Funding. No funding or sponsorship was received for this study or publication of this article.

Authorship. All named authors meet the International Committee of Medical Journal Editors (ICMJE) criteria for authorship for this article, take responsibility for the integrity of the work as a whole, and have given their approval for this version to be published.

Author Contributions. All authors contributed to the manuscript conception and design. All authors commented on previous versions of the manuscript. All authors read and approved the final manuscript.

Disclosures. Toshitatsu Nogita, Yuko Nomura and Ichiro Kurokawa, have nothing to disclose.

Compliance with Ethics Guidelines. This article is based on previously conducted studies 
and does not contain any new studies with human participants or animals performed by any of the authors.

Open Access. This article is licensed under a Creative Commons Attribution-NonCommercial 4.0 International License, which permits any non-commercial use, sharing, adaptation, distribution and reproduction in any medium or format, as long as you give appropriate credit to the original author(s) and the source, provide a link to the Creative Commons licence, and indicate if changes were made. The images or other third party material in this article are included in the article's Creative Commons licence, unless indicated otherwise in a credit line to the material. If material is not included in the article's Creative Commons licence and your intended use is not permitted by statutory regulation or exceeds the permitted use, you will need to obtain permission directly from the copyright holder. To view a copy of this licence, visit http://creativecommons.org/licenses/by$\mathrm{nc} / 4.0 /$.

\section{REFERENCES}

1. Plewig G, Melnik, Chen WC, editors. Acne clinic: morphogenesis. Plewig and Kligman's acne and rosacea. 4th ed. Springer; 2019. p. 63-68.

2. Katsambas AD, Cunliffe WJ, Zouboulis CC, et al. Clinical aspects of acne vulgaris. In: Zouboulis CC, et al., editors. Pathogenesis and treatment of acne and rosacea. Berlin: Springer; 2014. p. 213-21.

3. Dreno B, Gold LS. Acne scaring: why we should act sooner rather than later. Dermatol Ther (Heiderberg). 2021;11:1075-8.

4. Nogita T. Laser therapy for acne. JJSLM. 2010;31:61-4 (in Japanese).

5. Tan J, Boudes V, Bissonnette R, et al. Prospective study of pathogenesis of atrophic acne scars and role of macular erythema. J Drugs Dermatol. 2017;16: 567-73. 